\title{
Chico Buarque e a construção de gênero em canções forjadas na homoafetividade: da critica feminista à teoria queer
}

\author{
Chico Buarque and the gender contruction in songs forged \\ on homoafectiveness: from feminist criticism to queer theory
}

Camila Fonseca de Oliveira Calderano

Instituto Federal de Ciência e Tecnologia de Minas Gerais

Márcia Almeida

Universidade Federal de Juiz de Fora

DOI: https://doi.org/10.5902/2176148537253

\begin{abstract}
Resumo: Este artigo analisa duas canções do compositor Chico Buarque (Bárbara 1972/1973 e Mar e Lua - 1980) a partir da perspectiva de construção do gênero feminino em uma lógica não excludente. As canções em tela não apresentam a mulher através dos modelos convencionais e percebem a multiplicidade das sexualidades humanas, questionando a naturalização das identidades heteronormativas a partir da representação marginalizada e estigmatizada da homoafetividade. Além disso, em consonância com outras canções de Chico Buarque, representam uma crítica social à opressão e à marginalização dos homossexuais.
\end{abstract}

Palavras-chave: Feminino. Homoafetividade. Gênero. Chico Buarque.

Abstract: This article analyses two songs by popular singer-songwriter Chico Buarque (Bárbara - 1972/1973 and Mar e Lua - 1980) through the lens of female gender construction in a non-excludent logic. The songs presented doesn't show the women figure througt the conventional models and perceive the multiplicity of human sexuality, questioning heteronormative indentities' naturalization via the marginalized and stigmatized representation of homoafectiveness. Furthremore, in consonance with Chico Buarque's songbook, these two songs represent a social critique of the oppression and marginalization of homosexuals.

Keywords: Feminim. Homoafectiveness. Gender. Chico Buarque. 


\section{Introdução}

A intensa valorização dada à mulher na obra de Chico Buarque sugere, para além de uma determinação inconsciente, que influencia a disposição e as inclinações do poeta, um interesse pelo ente social-

Camila mente marginalizado. Os elementos que transgridem o convencional Fonseca de são constantes em sua obra desde o princípio e é nessa vertente que Oliveira a representação da mulher lésbica, assim como de transexuais ou Calderano anti-heroínas ${ }^{1}$ etc., encaminha para a consolidação de um tempo de novos paradigmas, os quais são firmados a partir da ruptura, das Márcia descontinuidades, da descentralização e da fragmentação. Suas canAlmeida ções são, muitas vezes, um exercício de crítica social e, nesse sentido, algumas das letras podem ser entendidas como ressonância de uma época e de práticas sociais.

Este artigo pretende desvelar o universo simbólico, metonimicamente estruturado nos códigos da cultura e da sociedade brasileiras, de construção da representação de gênero a partir de duas canções, das décadas de 1970 e 1980. Tais canções mostram-se em sintonia com as reivindicações e reflexões das feministas ao aliar a questão política à discussão sobre a marginalidade/subalternidade de classe e gênero ao mesmo tempo em que a aprofunda quando trata das esferas duplamente marginalizadas e oprimidas dentro do sistema de gênero, como é o caso dos/das homossexuais.

\section{Identidade e literatura}

A partir do final do século XX, uma modificação estrutural alterou as sociedades modernas, o que induziu ao esfacelamento e à fragmentação do cenário anterior, o qual, por meio de concepções ortodoxas (de sexualidade, de etnia, de classe e nacionalidade), tinha nos fornecido sólidos limiares para a análise dos indivíduos sociais num passado recente. Essas transformações estruturais seriam então responsáveis pela mudança de identidades pessoais e estariam abalando a imagem que temos de nós próprios como sujeitos integrados.

Tendo a dimensão de que a identidade é, portanto, uma esfera móvel, continuamente em formação e transformação no que se refere à configuração de nossa representação, é preciso também ter em

1 Canções como "Geni e o Zepelim" (1978/1979) e "Sob Medida" trazem à tona a enunciação de mulheres em suas vertentes extremamente oprimidas, quais sejam, nesses casos específicos: a mulher travesti e a mulher que não se encaixa nos padrões de Mulher (que M maiúsculo), arquétipo do grande feminino. 
mente que o sujeito irá assumir identidades diferentes em diferentes momentos, identidades que não são unificadas ao redor de um "eu" coerente. Assistimos também, conforme Stuart Hall (1999), à existência de identidades contraditórias dentro do próprio sujeito, apontando para direções distintas, de tal modo que nossas identificações estão sendo continuamente deslocadas. Ou seja, na medida em que os sistemas de representação cultural se multiplicam, identificando novos sujeitos, por vezes co-habitantes em um mesmo eu, somos confrontados por uma multiplicidade desconcertante e cambiante de identidades possíveis, com cada uma das quais poderíamos nos identificar, ao menos temporariamente (HALL, 1999).

É por esse prisma que a crítica literária tem destinado especial atenção a aspectos decorrentes dos estudos culturais. É imperativo

Chico Buarque e a construção de gênero em canções forjadas na homoafetividade compreender o elemento literário como modo de expressão cultural de vozes que entram em concorrência com a aparente hegemonia do sujeito tradicional. Desde a segunda metade do século passado, especificamente a partir da década de 1960, acompanhamos um progressivo questionamento da concepção de sujeito universal, que caracterizaria a literatura. Com o desmantelamento dessa concepção de sujeito e a percepção das várias identidades, antes subestimadas, abre-se lugar para abordagens que levem em consideração a heterogeneidade do sujeito.

Nesse sentido, flagramos o surgimento de uma crítica cultural que retirou a literatura do isolamento que a mantinha incólume de questões subalternas. Os novos paradigmas dos estudos literários, ao se confrontarem com as vozes esquecidas (ou subestimadas) e a heterogeneidade de seus discursos, põem em xeque os próprios critérios de avaliação crítica que formaram o cânone literário.

Linda Hutcheon (1991) nos assegura que, a partir de uma perspectiva descentralizada, o marginal e aquilo que chama de excêntrico, em termos de classe, raça, etnia ou orientação sexual, vão assumir importância diferenciada. Reconheceremos a partir de então que nossa cultura não é o monólito homogêneo, ou seja, masculina, classe média, heterossexual, branca e ocidental. Nesse ínterim, a literatura se converte em um espaço no qual as identidades são reescritas narrativamente, a partir de tensões sobre os suportes discursivos que sustentam e legitimam organismos de poder constituídos historicamente. 


\section{Os novos sujeitos e os estudos de gênero: a influência do movimento feminista}

Joan Wallach Scott (1990), ao estudar o gênero como categoria de análise histórica, explica que a teorização do gênero diz respeito a uma

Camila forma primária de dar significação às relações de poder, ou ainda que o Fonseca de gênero é um campo primário, no interior do qual ou por meio do qual, Oliveira o poder se articula. Dando continuidade à argumentação, diz que os hisCalderano toriadores/as historiadoras da arte foram responsáveis por possibilitar a emergência de um novo território ao extrair implicações sociais das Márcia representações literárias de homens e mulheres. Nesse sentido, tamAlmeida bém as interpretações são baseadas na concepção de que as linguagens conceituais empregam a diferenciação "para estabelecer o significado e que a diferença sexual seria uma forma primária para dar o significado à diferenciação" (SCOTT, 1990, p. 89). A autora conclui que:

\footnotetext{
$O$ gênero, então, fornece um meio de decodificar o significado e de compreender as complexas conexões entre várias formas de interação humana. Quando os/as historiadores/as buscam encontrar as maneiras pelas quais o conceito de gênero legitima e constrói as relações sociais, eles/elas começam a compreender a natureza recíproca do gênero e da sociedade e as formas particulares e contextualmente específicas pelas quais a política constrói o gênero e o gênero constrói a política (SCOTT, 1990, p. 89).
}

Em “A tecnologia do gênero", de Teresa de Lauretis, lemos que os/ as cientistas sociais feministas denominam sistema sexo-gênero aquele que historicamente estabeleceu as concepções culturais de masculino e feminino como duas categorias complementares, as quais, entretanto, se excluem mutuamente. Nelas, os seres humanos são classificados e formam, dentro das mais diversas culturas, um sistema de gênero, ou seja, um sistema simbólico de significações que relaciona o sexo a conteúdos culturais de acordo com valores e hierarquias sociais. Diz-nos a autora que, embora os significados possam variar de uma cultura para a outra, qualquer sistema de sexo-gênero está relacionado a fatores econômicos e políticos. Nesse sentido, “a construção cultural do sexo em gênero e a assimetria que caracteriza todos os sistemas de gênero através das diferentes culturas (embora cada qual a seu modo) são entendidas como sendo ligadas à organização da desigualdade social" (LAURETIS, 1994, p. 214). 
O sistema sexo-gênero, assim, seria tanto "uma construção sociocultural quanto um aparato semiótico, um sistema de representação que atribui significado (identidade, valor, prestígio, status dentro da hierarquia social etc.) a indivíduos dentro da sociedade" (LAURETIS, 1994, p. 215). Angela Arruda (2002), por sua vez, expõe que a teorização sobre gênero, assim como outras contribuições importantes a ela relacionadas, como a teoria feminista, surgem contrariando o paradigma dominante da época. A teoria feminista, nesse sentido, seria um produto típico dos nossos tempos e da transição paradigmática, tanto quanto as teorias da representação social ou de gênero e outras que, em sua maneira, surgem como novas ferramentas conceituais para analisar ângulos da realidade postos em pauta por novos olhares. Diz a autora que tanto a TRS ${ }^{2}$ quanto as teorias feministas nascem "na

Chico Buarque e a construção de gênero em canções forjadas na homoafetividade mesma conjuntura de degelo dos paradigmas para o qual concorrem. $\mathrm{Na}$ verdade, trata-se de um zeitgeist que percorre as ciências, marcado pela necessidade de novos instrumentos conceituais que se afinem com os tempos que correm" (ARRUDA, 2002, p. 131).

No Brasil, embora o movimento feminista existisse anteriormente, sua conjuntura era notadamente diferenciada. Céli Pinto (2003), no primeiro capítulo de O Feminismo no Brasil: suas múltiplas faces, intitulado "Em busca da cidadania", estuda o conjunto diverso de manifestações do movimento feminista, identificando duas tendências, que tiveram início no final do século XIX e se estenderam pelas três primeiras décadas do século XX.

De acordo com a autora supracitada, a primeira tendência teria como foco o movimento sufragista liderado por Bertha Lutz, identificada como feminismo "bem comportado" para sinalizar o caráter conservador desse movimento, o qual não questionava a opressão da mulher. Nesse sentido, a luta para a inclusão das mulheres à cidadania não se caracterizava pelo desejo de alteração das relações de gênero, mas como um complemento para o bom andamento da sociedade. A segunda tendência de feminismo, "malcomportado", seria a vertente que reúne uma gama heterogênea de mulheres (intelectuais, anarquistas, líderes operárias) que, além do político, defendem o direito à educação e falam em dominação masculina, abordando temas que, para a época, eram delicados, como, por exemplo, a sexualidade e o divórcio.

2 Teoria das Representações Sociais. 
Constância Lima Duarte (2003), diferentemente, não enxerga essas manifestações de modo estático. E, em "Feminismo e literatura no Brasil" (2003), propõe a divisão histórica do movimento em quatro grandes ondas. Diz a autora:

Camila

Fonseca de

Oliveira

Calderano

Márcia

Almeida

310
Considerando que essa história teve início nas primeiras décadas do século XIX - o momento em que as mulheres despertam do 'sono letárgico em que jaziam', segundo Mariana Coelho -, quero sugerir a existência de pelo menos quatro momentos áureos na história do feminismo brasileiro. Longe de serem estanques, tais momentos conservam uma movimentação natural em seu interior, de fluxo e refluxo, e costumam, por isso, ser comparados a ondas, que começam difusas e imperceptíveis e, aos poucos (ou de repente) se avolumam em direção ao clímax - o instante de maior envergadura, para então refluir numa fase de aparente calmaria, e novamente recomeçar (DUARTE, 2003, p. 152).

Sobre a real concretização do movimento, assegura a autora que as décadas em que esses momentos-onda teriam obtido maior visibilidade seriam em torno de 1830, 1870, 1920 e 1970, que seriam os "momentos áureos" na história das lutas feministas.

Sem pretender, evidentemente, exaurir o sentido de uma experiência tão multifacetada como o feminismo, buscamos aqui um recorte que nos auxilie a entender a propulsão das demandas sociais das mulheres na vertente cultural e artística do período aqui estudado. Interessa-nos, pois, o que Duarte (2003) denomina como quarta onda, a da revolução sexual e da literatura. Diz a autora que os anos setenta do século $\mathrm{XX}$ foram capazes de alterar radicalmente os costumes e transformar as reivindicações mais ousadas em algo normal. As consequências começam a ser sentidas no âmbito político, como explica a seguir:

No campo político, as mulheres começam a ocupar espaço nos partidos e a disputar as eleições, nas diversas instâncias do poder, mas não ainda no ritmo desejado. E mesmo nas últimas décadas do século XX assistimos a todo instante o registro de "pioneiras", pois a mídia não se cansa de noticiar as conquistas femininas que ocorrem a todo instante. Um dia é a primeira prefeita de uma grande capital, em outro é a primeira governadora, ou senadora, ministra, 
e por aí vai. Na década de 1980, grupos feministas ultrapassaram as divergências partidárias e se aliaram às vinte e seis deputadas federais constituintes - o "charmoso" "lobby do batom" - como forma de garantir avanços na Constituição Federal, tais como a desejada igualdade de todos os brasileiros perante a lei, sem distinção de qualquer natureza (DUARTE, 2003, p. 166-167).

Chico Buarque

e a construção

A autora dá continuidade explicando que, no campo literário, algumas escritoras se posicionariam frente ao governo ditatorial ${ }^{3}$, revelando com coragem suas posições políticas.

Ainda nesse sentido, Cynthia Andersen Sarti (2004), em artigo intitulado "O feminismo brasileiro desde os anos 1970: revisitando uma trajetória", focaliza a relação entre o contexto de autoritarismo político de gênero em canções forjadas na homoafetividade e a forma adquirida pelo feminismo no Brasil. Há, de acordo com a autora, evidente importância do contexto de luta de classe e contra a ditadura para o movimento no Brasil, o que baliza as publicações inaugurais das feministas dos anos 70, que nos chegam, por exemplo, através dos jornais "Brasil Mulher" e "Nós, Mulheres".

O movimento feminista brasileiro que surge nos anos 70 se caracteriza, assim, por um intenso compromisso político. Além disso, o ano de 1975 foi considerado como Ano Internacional da Mulher, logo estendido por todo o decênio (de 1975 a 1985), tal o estado de penúria da condição feminina, e tantas as metas para eliminar a discriminação. Diz a autora:

\footnotetext{
Uma confluência de fatores contribuiu para a eclosão do feminismo brasileiro na década de 1970. Em 1975, a ONU declara o Ano Internacional da Mulher, pelo impacto que já se fazia sentir do feminismo europeu e norte-americano, favorecendo a discussão da condição feminina no cenário internacional. Essas circunstâncias se somavam às mudanças efetivas na situação da mulher no Brasil a partir dos anos 1960, propiciadas pela modernização por que vinha passando o país (...), pondo em questão a tradicional hierarquia de gênero (SARTI, 2004, p. 39, grifos nossos).
}

3 Um exemplo é Nélida Piñon, que integrou o processo de redação do Manifesto dos 1000 contra a censura e a favor da democracia no Brasil. No ano de 1981, a escritora lançava o livro Sala de arma, composto de contos que se estruturavam em torno dos encontros e desencontros amorosos. Nélida tornou-se a primeira mulher a tomar posse como presidente da Academia Brasileira de Letras, e apenas bem recentemente declarou-se feminista. 
Além disso, nos parece importante destacar a existência de duas tendências fundamentais, dentro da corrente feminista, que se fizeram fecundas durante o movimento de mulheres nos anos 1970 e que acabaram por sintetizar o próprio movimento. A primeira ten-

Camila dência estaria dirigida para a atuação pública das mulheres, através Fonseca de da intensa investida em sua organização política. Nesse sentido, o Oliveira movimento concentrava-se principalmente nas questões relativas ao Calderano universo do trabalho, à saúde, ao direito e à redistribuição de poder entre os sexos. Essa corrente posteriormente buscaria influenciar as Márcia políticas públicas, utilizando os "canais institucionais criados dentro Almeida do próprio Estado, no período da redemocratização dos anos 1980" (SARTI, 2004, p. 43). A segunda vertente focaria suas preocupações no 312 fluido terreno da subjetividade, dando atenção especial às relações interpessoais e tendo no mundo privado seu campo privilegiado de atuação. Suas manifestações estariam circunscritas principalmente aos grupos de estudos, de reflexão e de convivência.

A esse contexto de esfacelamento dos antigos paradigmas, cujo resultado é também a resistência das mulheres à ditadura, alinham-se as mudanças pelas quais foi passando o país durante a fase mais amena do regime autoritário. Além disso, Linda Hutcheon afirma que o movimento também surge e se consagra como consequência da reorganização de uma estrutura ampla e mundial, onde se passam a considerar também as margens e as fronteiras sociais, promovendo, claramente, um afastamento em relação à centralização, aos conceitos de eterno e universal. Nessa medida, o regional, o local e o não-totalizante são reafirmados à medida que o centro vai se tornando uma ficção (HUTCHEON, 1991).

Dando continuidade ao raciocínio, a autora afirma que quando o centro começa a dar lugar às margens, quando a universalização totalizante começa a desconstruir a si mesma, a complexidade das contradições que existem dentro das convenções, como as de gênero, por exemplo, começam a ficar visíveis. Assim, a heterogeneidade reivindicada não virá a assumir a forma de um conjunto de sujeitos individuais fixos, mas, em vez disso, passará a ser concebida como um fluxo de identidades que se contextualizam e se condicionam ao emaranhamento de gênero, classe, raça, identidade étnica, preferência sexual, educação, função social etc. Para este trabalho, nos importa a concepção que começa a perceber a existência de mulheres, no plural, desmistificando a unicidade de um sujeito Mulher, cujas características foram, por séculos, cristalizadas em torno de um eu coerente. 
$\mathrm{Na}$ visão de Hutcheon, os negros e as feministas, os etnicistas e os gays, as culturas nativas e do "Terceiro Mundo" não formam movimentos monolíticos, mas constituem uma diversidade de reações a uma situação de marginalidade e ex-centricidade percebida por todos. Resulta, portanto, no que chamou de "efeitos liberadores" em razão do deslocamento da linguagem da alienação (não-identidade) para a linguagem da descentralização (diferença), porque o centro utilizado para funcionar como pivô entre opostos binários sempre privilegiava um dos lados: branco/negro, homem/mulher, eu/outro, intelecto/corpo, Ocidente/Oriente, objetividade/subjetividade (HUTCHEON, 1991, p. 90).

A partir do momento em que o centro é considerado como uma elaboração, uma ficção, e não como uma realidade fixa e imutável, afirma Hutcheon que o "velho ou-ou começa a desmoronar",

Chico Buarque e a construção de gênero em canções forjadas na homoafetividade e o novo "e-também" da multiplicidade e da diferença abre novas possibilidades.

\section{Crítica feminista e a leitura crítica a partir da perspectiva queer}

A crítica feminista, desenvolvida a partir da segunda metade do século $\mathrm{XX}$, é frequentemente bipartida em duas modalidades de estudo. Segundo Elaine Showalter (1994), uma delas se concentra na(s) mulher(es) como escritora(s), atuando no resgate de obras escritas por mulheres e que, no decorrer do tempo, foram renegadas ou postas à sombra das obras de autoria masculina, além de procurar detectar, através do estilo, do discurso e da temática, a relevância da fala feminina. A outra vertente de ação da crítica feminista tem por meta fazer uma releitura de obras literárias, independentemente da autoria ser feminina, considerando a experiência e representação da mulher. Esboça nesse sentido, a questão da leitura feminista como "ação intelectual libertadora" (1994, p. 26). Diz a autora sobre as formas de crítica ou leitura feministas:

\footnotetext{
Esse conflito revigorante com a literatura, que chamarei de leitura feminista ou crítica feminista, é, em essência, uma forma de interpretação, uma das muitas que qualquer texto complexo irá acomodar e permitir. É difícil propor coerência teórica numa atividade por natureza tão eclética e diversificada (SHOWALTER, 1994, p. 26).
} 
Eliane Showalter irá considerar, nesse sentido, dentro das modalidades de crítica, uma vertente ideológica, que se refere à leitora, também denominada leitura feminista ou crítica feminista, que privilegia imagens e estereótipos de mulher veiculados pela literaCamila tura, independentemente da autoria. Essa forma pode ter cunho liFonseca de bertador, uma vez que pode desconstruir os modelos veiculados pela Oliveira literatura. É justamente desse ponto que nasce, neste trabalho, uma Calderano perspectiva queer. Ou seja, ao perceber a multiplicidade das sexualidades humanas, a teoria queer nos permite questionar a naturaliMárcia zação das identidades heteronormativas a partir da representação Almeida marginalizada e estigmatizada da homoafetividade.

É interessante notar que, embora a diferenciação entre sexo e gênero seja fundamental para a crítica feminista, uma vez que o gênero não é entendido como identidade primordial absoluta, mas como um dado culturalmente construído, que acompanha as mudanças da própria cultura, a própria ideia de desconstrução desse sistema sexo-gênero, ou seja, da percepção do gênero como uma categoria moral, feita e refeita pelo contexto cultural, se revelou, dentro dos limites da crítica feminista, heteronormativa.

Judith Butler (1990) distingue que, como pudemos perceber nas análises anteriores, a tentativa de unidade feminina por parte dos movimentos feministas se origina em função de uma ação política que, embora útil, em determinado momento, para unir as mulheres na luta por direitos, iria, porém, pressupor uma identidade igualmente totalizante. Nesse sentido, a estabilidade dessa identidade fundada na unidade pressupõe a negação de outros arranjos e possibilidades do ser feminino e, por isso mesmo, segundo a autora, é incapaz de perpetrar as transformações e mudanças políticas reivindicadas.

Embora seja preciso levar em consideração as condições de produção dos discursos - sujeito do discurso, assunto/tema, destinatário e contexto - como pressupostos básicos para a análise, é preciso demonstrar, segundo Butler, como a ideologia se articula e opera através de ofuscações, dissimulações e fragmentações do texto, tendo em vista que "não há identidade de gênero por trás das expressões de gênero. Identidade é performativamente constituída pelas próprias ‘expressões' que são ditas como seus resultados” (BUTLER, 2004, p. 57). 
Nesse sentido, a emergência de oferta de novas formas de leitura acompanha uma realidade pouco estática. Buscando-se clarificar as ideologias e valores vigentes nos discursos articulados opera-se leitura crítica, podendo esta ser ou não feminista, ser ou não a partir de uma perspectiva queer. Uma vez que vivemos imersos em sistemas culturais estruturados a partir de códigos simbólicos, e de normas, que de algum modo regulam as práticas sociais, conceber novas formas de leitura será conceber novas formas discursivas e as transformar em ideologia.

Tratando este trabalho de autoria masculina, aqui nos interessa o que Showalter chamou de ação intelectual libertadora. Libertadora porque promove uma emancipação cujos desdobramentos estão presentes naquilo que se pretende tirar do texto. A leitura e a crítica que propomos, de duas canções de Chico Buarque, procuram desconstruir os processos

Chico Buarque e a construção de gênero em canções forjadas na homoafetividade ideológicos tradicionais, discutindo as representações femininas, a fim de colocar em evidência as questões de identidade e de gênero.

\section{A apresentação da lésbica}

As canções Bárbara e Mar e Lua, de 1972/1973 e 1980, respectivamente, compõem a construção da lésbica a partir da presença de sujeitos femininos em uma relação homoerótica cuja concretização é impossível em seu contexto sociocultural.

No segundo volume de 0 segundo sexo, de Simone de Beauvoir, há um capítulo intitulado A Lésbica. Nele a filósofa aponta, sobretudo, para questões psicológicas. Ao esbarrar nas sociais, entretanto, assevera a solidão da mulher homossexual:

A mulher só apresenta-se sempre como um pouco insólita; não é verdade que os homens respeitem as mulheres: eles se respeitam mutuamente através de suas mulheres - esposas, amantes, teúdas e manteúdas; quando a proteção masculina não se projeta mais sobre ela, a mulher fica desarmada em face de uma casta superior que se mostra agressiva, escarninha ou hostil (BEAUVOIR, 1990, p. 163).

É interessante perceber em que medida Beauvoir, já em 1949, antes, portanto, dos questionamentos atuais sobre os padrões da heteronormatividade, aponta para a exclusão, dentro do grande espectro do feminino (ainda que criticamente construído a partir do feminismo) das relações homoafetivas, as quais são duplamente subalternas. 
Adentrando na primeira canção, encontramos o clamor de Ana por Bárbara, viúva de Calabar, e o retorno de Bárbara para Ana, ao atender seu pedido. Há um enorme jogo de sedução na canção, que não anuncia o destino da relação. Faz-se um apelo, um convite. Bárbara é viúva e Ana é Camila prostituta. Alternadamente, as vozes das personagens são indicadas pelos Fonseca de seus nomes, que precedem as falas de uma e de outra. Obviamente, os Oliveira versos precedidos de "as duas" correspondem a uma fala conjunta:

Calderano

Márcia

Almeida

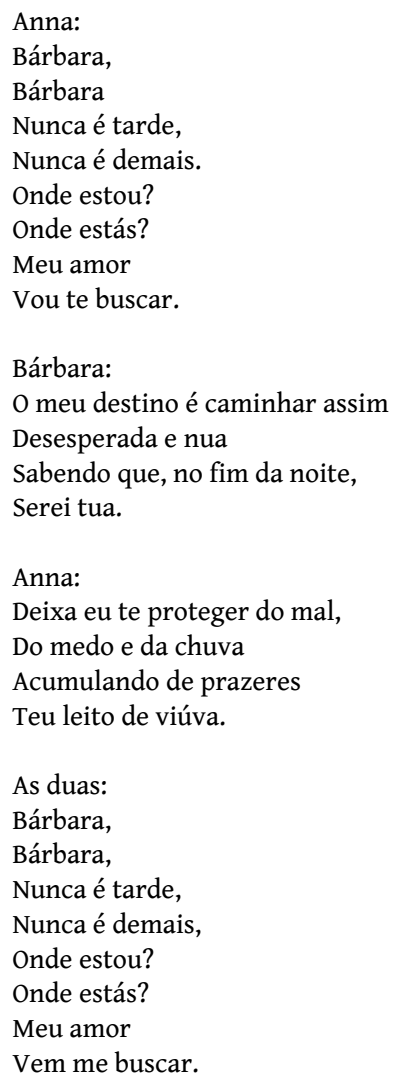

É interessante notar que algumas marcas discursivas habitualmente reservadas à construção do gênero masculino são transportadas para canção, como nos trechos "Deixa eu te proteger do mal, dos medos e da chuva" e "Vou te buscar", enunciados que querem desvelar a proteção e a atitude, símbolos da construção tradicional do gênero masculino. Por esse prisma, podemos conjeturar a não delimitação ortodoxa do gênero nas canções, ou seja, a impossibilidade de assentar determinadas marcas discursivas a um gênero ou outro, de modo que sua construção não seja excludente. 
Ao mesmo tempo, ainda que possamos interpretar uma ressignificação do gênero nessa canção, devemos chamar atenção para o fato de as relações homoafetivas cantadas por Chico encontrarem fatores que marcam a sua não realização, como a distância e a desesperança, para denunciar uma sociedade que resiste a aceitar qualquer experiência que esteja fora da norma heterossexual. Já no primeiro trecho de Bárbara aparece o desespero e o medo: "o meu destino é caminhar desesperada e nua". Vemos também a separação e a ausência: “onde estou, onde estás,/meu amor vem me buscar".

A referência à ideia da tentação cristã, como algo a que não devemos ceder, está presente na segunda parte da canção, quando Bárbara resolve viver uma paixão vadia, mesmo que agonizando, mesmo que em um poço escuro. A comparação da paixão à hemorragia sugere toda a

Chico Buarque e a construção de gênero em canções forjadas na homoafetividade sua carga de ilegalidade e imoralidade. Será através da ferida, que sangra sem parar, a vida das lésbicas de Bárbara.

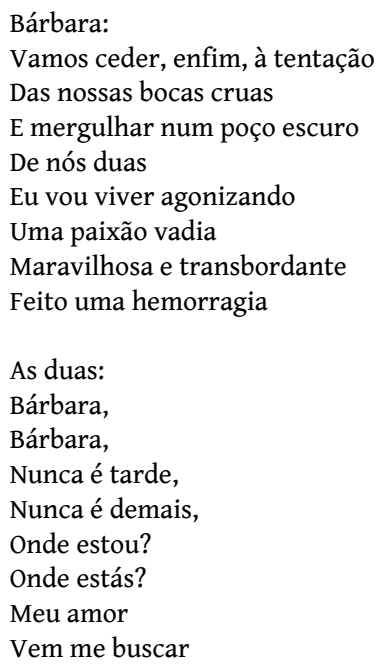

De modo mais contundente, Mar e Lua irá traçar a representatividade dos sentimentos femininos homoafetivos por meio da consciência que culmina no duplo suicídio. Extremamente lírica, a referência aos pares naturais que se enamoram, o mar e a lua, será cerne da canção, permeada por metáforas e personificações. Dividida em duas partes, a primeira delas adentrará na relação lesbiana e no preconceito. 
Camila

Fonseca de

Oliveira

Calderano

Márcia

Almeida
Amaram o amor urgente

As bocas salgadas pela maresia

As costas lanhadas pela tempestade

Naquela cidade

Distante do mar

Amaram o amor serenado

Das noturnas praias

Levantavam as saias

E se enluaravam de felicidade

Naquela cidade

Que não tem luar

Amavam o amor proibido

Pois hoje é sabido

Todo mundo conta

Que uma andava tonta

Grávida de lua

E outra andava nua

Ávida de mar

O amor de Mar e Lua é urgente, escandaloso, traz tempestade e lanha as costas. A cidade é longe do mar e não tem luar, ou seja, não tem romance, nem sonho, não tem lugar para elas. A ideia de uma felicidade proibida, que não se encontra no seu meio social, a cidade pequena e distante do mar, é claramente percebida no primeiro trecho. $\mathrm{O}$ amor reprimido, porém, hoje já é sabido e todo mundo conta:

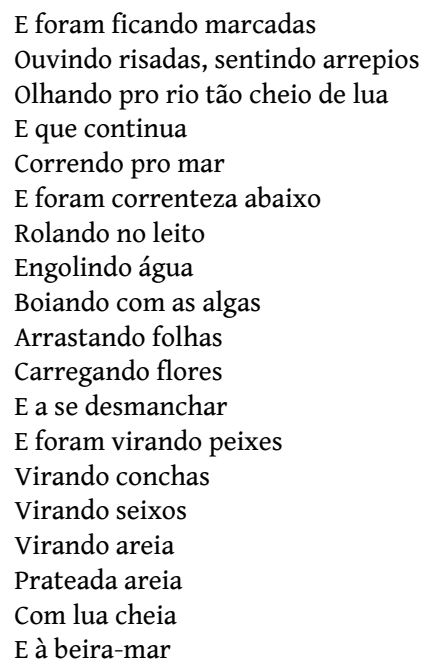

Os versos "E foram ficando marcadas/Ouvindo risadas, sentindo arrepios" denotam a marginalização sofrida. O verbo marcar, também usado para caracterizar a prostituta, que é carta marcada, 
alude aqui à segmentação criada a partir da descoberta da relação. Sobre a impossibilidade de instituição social homoafetiva, Beauvoir diz:

Como "perversão erótica", a homossexualidade feminina mais faz sorrir do que outra coisa, mas se implica um modo de vida suscita desprezo ou escândalo. Se há muita provocação e afetação na atitude das lésbicas, é porque elas não têm nenhum meio de viver sua situação com naturalidade: a naturalidade implica em não refletir sobre si mesmo, agir sem se representar os atos; mas as condutas de outrem levam sem cessar a lésbica a tomar consciência de si. Somente sendo bastante idosa ou dotada de grande prestígio social é que ela pode seguir o seu caminho com

Chico Buarque e a construção de gênero em canções forjadas na homoafetividade

Assim, o destino das lésbicas de Mar e Lua após o duplo suicídio, ainda que belíssimo, é o de aniquilamento. Somente o rio ainda era cheio de lua e ávido de mar.

Essas canções, como outras do compositor, compõem um mosaico de representações da(s) mulher(es) a partir de uma lógica não excludente e não opressora na medida em que não reproduzem um modelo consensual que anula as particularidades dos sujeitos. Ademais, é profundo o exercício da crítica aos preconceitos sociais que se assentam nas relações homoafetivas, reveladas na sua não concretização, no sofrimento e na solidão dos entes marginalizados. Ambas as canções revelam, além da sensualidade (em Bárbara) e do lirismo metafórico (em Mar e Lua), certo grau de desesperança (acentuado em Mar e Lua) que denuncia a não aceitação de qualquer experiência que esteja fora da norma heterossexual.

\section{Considerações Finais}

A partir da segunda metade do século XX, assistimos a uma reivindicação de heterogeneidades. No século XXI, consolidamos a perspectiva flexível e integradora. Dessa maneira, as identidades se formam no imbricamento de gênero, classe social, pertencimentos étnico-raciais, orientação sexual, educação, função social e geração, entre outros.

Chico Buarque, enquanto poeta contemporâneo e, por essa razão, imerso nas fissuras do tempo em que vive, congrega e promove as transformações do seu lugar, dando a possibilidade e a liberdade 
ao leitor para se identificar com suas vozes ideológicas. Tendo ciência de que tal deslocamento é fruto do próprio interesse do poeta, nos parece justo qualificar Chico Buarque como promulgador de um tempo em que se afirmavam novas e necessárias mulheres, inclusive

Camila aquelas cuja sexualidade não é regida pelo estatuto da heteronormaFonseca de tividade.

Oliveira As canções analisadas se mostram como material adequado ao Calderano questionamento da heteronormatividade e também apto para elucidar processos de exclusão de identidades não legitimadas em geral. NesMárcia se sentido, a leitura a partir de uma perspectiva queer deve operar a Almeida desconstrução das lógicas discriminatórias, desestabilizando conceitos e redes de poder que impõem a naturalização de certos discursos aos 320 sujeitos. Discursos esses que limitam e reprimem.

Nesse sentido, sendo o discurso de poetas um lugar privilegiado de exercício de poder, situamos as duas canções analisadas neste estudo em um tempo de novos paradigmas, os quais são firmados a partir da ruptura, das descontinuidades, da descentralização e da fragmentação identitária e de gênero.

\section{REFERÊNCIAS}

ARRUDA, Ângela. Teoria das representações sociais e teorias de gênero. Cadernos de Pesquisa, n. 117, p. 127-147, novembro/ 2002. Disponível em: http://www.scielo.br/pdf/cp/n117/15555.pdf. Acesso em: 03/02/2019.

BEAUVOIR, Simone de. O segundo sexo: a experiência vivida. V. 2. Tradução de Sérgio Milliet. São Paulo: Nova Fronteira, Difusão Européia do Livro, 1990.

BUTLER, Judith. Problemas de Gênero. Rio de Janeiro: Civilização Brasileira, 2012.

DUARTE, Constância Lima. Feminismo e literatura no Brasil. Estudos Avançados 17 (49), 2003. Disponível em: http://www.scielo.br/pdf/ ea/v17n49/18402.pdf. Acesso em: 19/02/2019. 
HALL, Stuart. A identidade cultural na pós-modernidade. Trad. Tomaz T. da Silva e Guacira L. Louro. 3 ed. Rio de Janeiro: DP\&A, 1999.

HUTCHEON, Linda. Poética do pós-modernismo: história, teoria, ficção. Rio de Janeiro: Imago, 1991.

LAURETIS, Teresa de. A tecnologia do gênero. In: HOLLANDA, Heloísa Buarque de (Org.). Tendências e impasses: o feminismo como crítica da cultura. Rio de Janeiro: Rocco, 1994.

PINTO, Céli Regina Jardim. o feminismo no Brasil: suas múltiplas faces. São Paulo: Fundação Perseu Abramo, 2003. 119 p. (Coleção História do Povo Brasileiro). Disponível em http://www.scielo.br/pdf/ Chico Buarque e a construção de gênero em canções forjadas na homoafetividade ref/v12n2/23971.pdf. Acesso em: 14/11/2018.

SARTI, Cynthia Andersen. O feminismo brasileiro desde os anos 1970: revisitando uma trajetória. Estudos Feministas, Florianópolis, 12(2): 264, maio-agosto/2004. Disponível em: http://www.scielo.br/ scielo.php?script $=s c i \_p d f \& p i d=S 0104-026 X 2004000200003 \& \operatorname{lng}=e n \& n r m=i$ so\&tlng=pt. Acesso em 14/11/2018.

SCOTT, Joan Wallach. Gênero, uma categoria útil de análise histórica. Educação e Realidade, v. 16, n. 2. Porto Alegre, p. 5-22, jul-dez. 1990.

SHOWALTER, Elaine. A crítica feminista no território selvagem. In: HOLLANDA, Heloísa Buarque de (Org.) Tendências e impasses: o feminismo como crítica da cultura. Rio de Janeiro, Rocco, 1994. 
